\title{
Biphasic CT imaging of deep neck infections (DNIs): how does dual injection mode helps in differentiation between types of collections?
}

\author{
Lamya Eissa ${ }^{1}$ and Ahmed Mohamed Mehanna ${ }^{2^{*}}$ (1)
}

\begin{abstract}
Background: Deep neck infections are showing resurgence in the current era and still pose threatening diagnosis. CT is the gold standard imaging modality; still, the reported low sensitivity and specificity was suggested in view of monophasic injection technique.

The purpose of the study was to discuss the diagnostic accuracy of $C T$ with biphasic mode of injection using and a single scanning phase. The first 50-60 cc of IV contrast are injected at a slow rate of $1 \mathrm{cc} / \mathrm{s}$ to (tissue impregnation phase). The other 50-60 cc was injected at a high rate of $2 \mathrm{cc} / \mathrm{sec}$, approximately $1 \mathrm{~min}$ after the first injection. The single phase of scanning is made followed by multi-planar image analysis of collection. Discrimination of abscess versus phlegmon is made according to described criteria.
\end{abstract}

Results: Radiological diagnosis was made of 64/66 cases of abscess and two cases only had phlegmon. The 64 cases of abscess underwent drainage by ENT surgeon showing correctly diagnosed drainable abscess in 59 out of 64 cases and 5 falsely diagnosed as abscess proved to be non-drainable phlegmon. The two patients with radiological diagnosis of non-drainable phlegmons were correctly diagnosed.

Conclusion: The study achieved a high accuracy of 92\%. This is likely attributed to dual-phase technique that allows enhancement of the core of a phlegmon by slow interstitial phase, while combined dual injections allow enhancing the "rim enhancement sign" of abscess.

Keywords: $\mathrm{CT}$, Deep neck infections, Abscess, Biphasic injection

\section{Background}

Deep neck space infection (DNI) means infection in the potential spaces and fascial planes of the neck, either with abscess formation, phlegmon or cellulitis, or a combination of any of them [1]. Despite the improved diagnostic techniques and widespread availability of anti-microbial therapies, these infections are still serious and potentially life-threatening today as in the past with high morbidities and mortalities reported. The

\footnotetext{
* Correspondence: mehanna81@hotmail.com

2Otolaryngology Department, Alexandria Faculty of Medicine, Alexandria, Egypt

Full list of author information is available at the end of the article
}

underlying foci of DNIs are several in the head and neck, including teeth, adenoids, and salivary glands [1-3]. The commonest origin of DNI is yet different in many publications; in the pre-antibiotic era, most DNIs arose from tonsillo-pharyngitis, while today, dental infections are the most common cause [4-6]. These odontogenic (dental/peri-dental) infections are one of the most common causes especially in developing countries $[2,3]$. The odontogenic infections like peri-apical lesions with pulp necrosis and bacterial invasion into peri-apical tissues associated with periodontal pockets cause DNIs [4].

Although acute neck infections are easily diagnosed by clinical examination, correct localization may be 
challenging and maybe even impossible without crosssectional imaging in many cases. The extent of deep space involvement is particularly difficult to be accurately made by clinical evaluation, with accurate localization of infection could be made in only $42.9 \%$ of cases in one series and in another series, the extent of deep neck space infection was under-estimated in up to $70 \%$ of cases $[7,8]$. The radiologists must be familiar with the anatomy of the deep cervical fascia and the spaces bounded by these fascial planes; this is because the layers of the deep cervical fascial are not readily well seen on contrast-enhanced CT [9].

Computed tomography (CT) scans of the head and neck is a critical component in the evaluation of the extent of deep neck infection because physical examination alone can misidentify the involved space and the number of involved spaces in $70 \%$ of cases. CT scans with intravenous contrast provide good visualization of most bony and soft tissue structures and fascial spaces of the head and neck. The intravenous contrast allows visualization of the great neck vessels and enhancement of areas of inflammation and allows identification of collections and evaluation of suspect complications [10].

CT is also helpful in the identification of underlying causes in most of the cases allowing for adequate evaluation of the oral cavity infections and suspected dental or peri-dental infections. Enhanced CT can detect rimlike enhancement of fluid collections and associated cellulitis and myositis, as well as the dental disease itself. Careful evaluation of $\mathrm{CT}$ images obtained with bone window settings may reveal the causative caries as defect of the white dense dentin, with depiction of peri-apical lucencies and mandibular cortical dehiscences, as well as signs of osteomyelitis or periosteal reaction $[10,11]$.

Acute tonsillitis can be radiologically characterized by increased size of the tonsils and increased density/enhancement as seen on a contrast-enhanced CT. The increased density reflects contrast enhancement of tonsillar septa ("Tigroid tonsils"), with a tiny area of fluid liquefaction detected in early infections in the absence of walls $[12,13]$.

A drawback of CT in DNI imaging is that it cannot reliably differentiate between the non-drainable phleg$\mathrm{mon} /$ cellulites and drainable abscesses in some cases because both entities commonly appear as hypo-dense collections with peripheral enhancement; specificity measured in literature can be only $70-80 \%$ although the overall sensitivity for DNI detection is up to $80-90 \%$ [13-16]. A positive correlation between CECT and surgery or surgical drainage has been reported to be approximately $75 \%$ in adult and pediatric patients [15-17]. The specificity of CT can be improved to $82 \%$ with lesions larger than $3.5 \mathrm{~cm}$ in some cases. Also, it can be increased by a delayed post-contrast CT image taken after several minutes depicting subtle central enhancement in a poorly liquefied lesion, thus avoiding unnecessary surgery and still caries the dis-advantage of excessive exposure. The presence of intra-lesional air indicated abscesses in all cases with no attempted drainage $[15,17-20]$.

The distinction between tonsillar cellulitis and tonsillar abscess is important because the treatment is quite different in both. When the imaging features of a fluid attenuation collection with an enhancing wall are applied, the accuracy for the detection of a drainable abscess ranges from 63 to $77 \%$ in both pediatric and adult patient populations. If combined with an additional imaging criterion of an irregular or scalloped abscess wall, it increases specificity but decreases sensitivity in diagnosis [18-20].

CT can also be helpful to detect a list of expected complications. Mediastinitis with or without collections results from downward extension of an infection that involves the spaces that extend the length of the neck (e.g., retropharyngeal) or the anterior visceral space [21]. The so-called Lemierre syndrome, or suppurative thrombophlebitis of the internal jugular vein, results from the extension of the infection into the carotid space, showing pathognomonic findings of neck swelling and IJV thrombus (by imaging), and evidence of pulmonary emboli. Carotid artery pseudoaneurysm (mycotic aneurysm) or rupture may present with a pulsatile cervical mass and often diagnosed by imaging CT angiographic techniques [22].

Ultrasound though supposed to be more accurate than CECT in differentiating a drainable abscess from cellulitis and additionally is portable, inexpensive, and available at most institutions, it is difficult to interpret, subject to the skill level of the operator, cannot visualize deeper fascial lesions, and does not provide the anatomic delineation necessary for planning the surgical approach to a DNI. MRI provides better soft tissue definition than CECT, with added privilege of avoiding exposure to radiation and allergenic CT contrast material. Moreover, magnetic resonance angiography (MRA) is especially useful in evaluating vascular complications, such as IJVT and carotid artery aneurysm \pm rupture. Unfortunately, MRI is expensive and requires a lengthy scan time in comparison with CECT, which is much more helpful in emergency settings [21].

The aim of this study is to examine the accuracy (sensitivity and specificity) of the bi-phasic CT in the differentiation of collections. The term biphasic means double mode of injection with single scanning; this encompasses two modes of injection: The first is slow (interstitial) and it is expected to allow for more adequate interstitial concentration of injected contrast inside the soft tissues; thus, this phase of injection is 
called impregnation. This is supposed to enhance the center of phlegmon so it would not appear hypo-dense as abscess core. The second phase is rapid (vascular phase) which is made to enhance vascular and other soft tissue structures. The application of two phases of contrast injection is suggested to allow for the abscess wall of different maturations to accumulate contrast so that enhancing rom sign should appear in images of abscesses.

\section{Methods}

Patients of all ages and sex with clinically suspect diagnosis of deep neck infection by ENT at ENT or emergency departments are either suspected to involve superficial or deep fascial plane.

Exclusion criteria included the following:

1) Known contraindications to CT, e.g., pregnancy

2) Known contraindications to IV contrast, e.g., renal insufficiency (creatinine clearance is calculated according to the Cockcroft equation: ((140 - age) wt $\times 0.85)$

3) Patients who received specific treatment (antibiotics or attempted drainage) prior to the examination

4) Known post-operative infections,

5) Peri-vertebral/para-spinal abscesses; these are mostly related to spinal infections

6) Known or highly suggested specific infections as tuberculosis and others

7) Infections superadded on cystic lesions (branchial or thyro-glossal cysts)

8) Inflammatory non-infectious cases/mimics as calcific tendinitis

9) The emergency pediatric visceral space infections (as epiglottitis), where pre-operative quick radiographs are only made.

All the studied patients are subjected to the following: (1) full history taking and thorough clinical examination; (2) the medical ethics were considered: the patient should be aware of the examination, patient consent is obtained, the economic status of the patient is considered, and the patient has to get benefit from the examination; (3) written consent was taken by co-operative patients and verbally by non-cooperative patients, (4) multi-detector row $\mathrm{CT}$ with biphasic/dual intravenous contrast administration, and (5) drainage of collections by ENT specialist after identification of the site of collections by imaging.

\section{Imaging technique \\ CT technique}

CT assessment is performed following intravenous administration of contrast media (300 mg iodine/ml) in a biphasic manner as follows: The first $50-60 \mathrm{cc}$ of contrast medium are injected at a slow rate of $1 \mathrm{cc} / \mathrm{s}$ to impregnate the interstitial compartment. This is called slow/interstitial/impregnation phase. The second 50-60 cc of contrast medium are injected at a higher rate of 2 $\mathrm{cc} / \mathrm{s}$, starting approximately $1 \mathrm{~min}$ after the first injection; this is called vascular phase. This protocol usually provides an adequate opacification of the different neck structures, soft tissue, and vascular structure, thereby allowing and precise determination of vascular invasion and accurate interpretation of head and neck CT images. In pediatric population, the biphasic mode of injection is made using half the volume of contrast used for adults, with single scanning using half exposure dose.

\section{Scan parameters}

The examinations were done on Toshiba (Aquillion) 128-Multi-section scanner and scanning parameters were slice thickness $1 \mathrm{~mm}$, Gantry rotation time 0.6-0.9 $\mathrm{s}(0.75 / \mathrm{s})$, detector collimation $2 \mathrm{~mm}$, helical mode, field of view (FOV) for small, medium, and large patients, $\mathrm{kVp}$ and $\mathrm{mA}$ per slice $120 \mathrm{kV}$ p and approximately $\leq$ $240 \mathrm{~mA}$. Scans were performed to cover from the skull base to the aortic root.

\section{Reconstruction methods}

The thin slices were sent to the workstation (Toshiba and Vitrea Workstation), as well Osirix software on iMac computer. The data was available to view the data in axial, sagittal, and coronal planes. Thin slice acquisition and multiplanar capability allowed the precise location of the lymph nodes and its characters.

\section{Image analysis}

A) Making diagnosis of DNI and differentiation from other non-inflammatory pathologies: thick stranded platysma sign and fascial veiling/stranding are very helpful to differentiate DNI from other minims.

B) Comment is made on the spaces involved: masticator, submandibular space-SMS, sublingual abscess-SLS, para-pharyngeal-PPS,

Retropharyngeal-RPS, etc. Laterally is reported, as well as midline crossing. Communication or noncommunication of the collection is reported.

C) The collections are differentiated as follows:

A) Abscess is documented by the following features (solely or in combination): a very hypo-dense center reaching near fluid attenuation $(10-30 \mathrm{HU})$ in any small ROI within the center, peripheral rim irregular or regular enhancement (the rim can be thin or thick with high center to rim ratio), and internal air foci are highly suggestive of abscess. 
B) A phlegmon is differentiated by these imaging features: (1) soft tissue enhancing tumefaction; (2) a central hypo-density may be seen, still above the range of fluid attenuation more than $30 \mathrm{HU}$; (3) central foci of fluid can suggest internal microabscesses; and (4) thick irregular enhancing margin with a low center to rim ratio.

C) Cellulitis is diagnosed as purely veiling and reticular thickening of facial plane girth minimal to mild non-loculated fluid.

D) Retro-pharyngeal inflammations/infections are differentiated as follows: (A) the retropharyngeal effusion is diagnosed as simple clear fluid filling the RPS from side to side, rectangular or slightly ovoid. No mass effect; minimal distension of retropharyngeal space. No enhancing wall detected for effusion. (2) Retropharyngeal abscess is diagnosed as fluid filling the RPS form side to side, showing rounded or ovoid configuration; with moderate-to-marked mass effect, and enhancing wall. (3) Suppurative adenitis is unilateral to either side of RPS, showing rounded or ovoid configuration; mass effect varies according to nodal size. It can have enhancing wall, which can be thick representing the nodal remnant.

E) In cases of Tonsillo-pharyngitis: (1) Simple tonsillitis is diagnosed as "Tigroid" = Striated pattern of enhancing palatine tonsils. (2) Intra-tonsillar abscess is diagnosed by criteria similar to abscess in any other neck space. Simple tiny loculi with no walls are not considered abscesses. (3) Peri-tonsillar location is diagnosed as peripheral collection lateral to palatine tonsil pushing the tonsil medially.

F) Dental disease (caries) is reported by finding of defect of dense dental lamina overlying the tooth. Peri-dental disease is diagnosed by finding a lucency surrounding the apex of the unhealthy tooth. Mandibular changes are reported including: (i) a defect of buccal or lingual cortex, (ii) bony changes of medulla including erosions (permeative versus motheaten versus sclerosis), (iii) periosteal reaction is also reported \pm sub-periosteal abscess.

\section{Results}

There were 44 (66.7\%) male and 22 (33.3\%) female patients, with a female-to-male ratio of $2 / 1$. The mean age was 26 (Table 1). Considering radiological evidence of underlying cause, the causes of deep neck infections were identified in 64 patients. The most common cause of deep neck infection was odontogenic (34 cases = (51.5\%). Odontogenic causes were diagnosed through high-resolution bone CT. The dental disease ranged from isolated dental caries to more complicated dental and peri-dental inflammation. Mandibular changes were
Table 1 Distribution of the studied cases according to demographic data $(n=66)$ : age and sex

\begin{tabular}{|c|c|}
\hline & No. (\%) \\
\hline \multicolumn{2}{|l|}{ Sex } \\
\hline Male & $44(66.7 \%)$ \\
\hline Female & $22(33.3 \%)$ \\
\hline \multicolumn{2}{|l|}{ Age (years) } \\
\hline$<10$ & $2(3 \%)$ \\
\hline $10-20$ & $12(18.2 \%)$ \\
\hline $21-30$ & $23(34.8 \%)$ \\
\hline$>30$ & $29(43.9 \%)$ \\
\hline Median (Min.-Max.) & $26(4-60)$ \\
\hline Mean \pm SD & $29.8 \pm 12.9$ \\
\hline
\end{tabular}

noted in only 7 patients; those included mandibular bone marrow or cortical sclerosis, erosions, or mixed, while periosteal reaction was noted in only two cases and none of the patients had a sub-periosteal collection.

The second most common cause of deep neck infection was tonsillo-pharyngitis in 17 cases (25.8\%). The third commonest cause was suppurative adenitis encountered in 10 (15.2\%). Only two cases had trauma by ingestion of fish bone with posterior pharyngeal wall penetration into retropharyngeal abscess (3\% of cases). A single case had calcular submandibular sialadenitis with obstructive stone and ruptured ductal sialocele with abscess formation.

Only a small number of patients had radiological evidence of complications: 9 cases (13.6\%), as compared to none in 57 (86.4\%). Three patients had evidence of mediastinal extension; 2 of which are along the retropharyngeal pathway. A third one, a 5-year-old child, had this mediastinal extension along carotid space/Lincoln's highway into the middle mediastinum. One patient had Necrotizing fasciitis with gas formation and suspected underlying minimal disease that is disproportionate to the extent of inflammation. A young 23-year-old female patient had IJV thrombo-phlebitis with secondary simple RP effusion and a skin fistula.

Complications were seen in younger age groups: Bilateral thrombosed mycotic aneurysms were encountered in a 4-year-old child, being misdiagnosed as retropharyngeal abscess, and with diagnosis made following a complete MRI study and catheter occlusion of the aneurysm was made. Airway obstruction by kissing tonsils was seen in a 4-year-old boy while airway obstruction by extrinsic collections was seen in one patient. A 21-year-old patient had mediastinal spread along carotid space seen as longitudinal abscess, easily differentiated from thrombosed IJV by CT; this is called the Lincoln's highway (Fig. 1) 


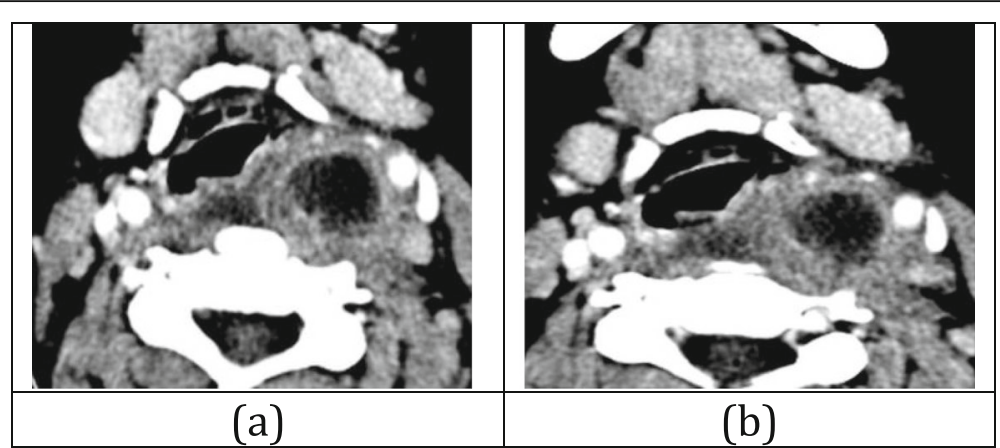

Fig. 1 A 21-year-old male shows a longitudinal collection of carotid space showing fluid attenuation and thin abscess rim wall. It is interposed between the IJV and CCA as depicted in axial and sagittal images ( $\mathbf{a}$ and $\mathbf{b}$ ), respectively, easily differentiated from thrombosed IJV and represent dangerous Lincoln's highway abscess. c Middle mediastinal extension

The spaces involved are detailed in Table 2, described as overlapping in the 66 patients. Nearly 15 patients showed multiple spaces involvement, and this is accepted for the nature of easily dissected fascial planes by dissecting fluids. Nine patients had isolated involvement of retropharyngeal space (two with fish bones, two with suppurative adenitis); 11 patients had isolated involvement of tonsils/tonsillar spaces. A single patient had isolated involvement of the right anterior cervical space, related to trickling inflammatory exudate from dental infection and mandibular osteomyelitis defect. The remaining 5 cases of anterior cervical space involvement were seen in combination with other spaces involvement b direct spread from contiguous spread. The remaining cases had a combination of two spaces involvement.

Table 3 shows the distribution of the studied cases according to different parameters: type of collection, laterality, underlying cause, and complications.

Table 2 Distribution of the studied cases according to spaces $(n=66)$

\begin{tabular}{ll}
\hline Spaces & No. (\%) \\
\hline SMS & $13(19.7 \%)$ \\
SLS & $13(19.7)$ \\
VS & $3(4.5 \%)$ \\
RPS & $12(18.2 \%)$ \\
Buccal & $4(6.1 \%)$ \\
MS & $15(22.7 \%)$ \\
ACS & $6(9.1 \%)$ \\
CS & $2(3 \%)$ \\
PPS & $7(10.6 \%)$ \\
Tonsillar & $15(22.7 \%)$ \\
Peritonsillar & $2(3 \%)$ \\
Parotid & $2(3 \%)$ \\
\hline
\end{tabular}

Table 3 Distribution of the studied cases according to different parameters: type of collection, laterality, underlying cause, and complications

\begin{tabular}{|c|c|}
\hline & No. (\%) \\
\hline \multicolumn{2}{|l|}{ Radiological diagnosis of collections } \\
\hline No abscess & $2(3 \%)$ \\
\hline Abscess & $57(86.4 \%)$ \\
\hline Phlegmon and abscess & $7(10.6 \%)$ \\
\hline \multicolumn{2}{|l|}{ Side } \\
\hline Left & $26(39.4 \%)$ \\
\hline Right & $20(30.3 \%)$ \\
\hline Midline & $6(9.1 \%)$ \\
\hline Bilateral & $14(21.2 \%)$ \\
\hline \multicolumn{2}{|l|}{ Cause } \\
\hline Unknown & $2(3 \%)$ \\
\hline Dental & $34(51.5 \%)$ \\
\hline Others & $30(45.5 \%)$ \\
\hline Suppurative adenitis & $10(15.2 \%)$ \\
\hline Calcular sialadenitis & $1(1.5 \%)$ \\
\hline Tonsillitis & $17(25.8 \%)$ \\
\hline Trauma by fish bone & $2(3 \%)$ \\
\hline \multicolumn{2}{|l|}{ Complications } \\
\hline None & $57(86.4 \%)$ \\
\hline Positive & $9(13.6 \%)$ \\
\hline Mediastinal extension & $3(4.5 \%)$ \\
\hline Necrotizing fasciitis-air & $1(1.5 \%)$ \\
\hline Linear abscess Lincoln's pathway to the mediastinum & $1(1.5 \%)$ \\
\hline IJV thrombo-phlebitis-RP effusion-skin fistula & $1(1.5 \%)$ \\
\hline Bilateral thrombosed mycotic aneurysms & $1(1.5 \%)$ \\
\hline Way obstruction by kissing tonsils & $1(1.5 \%)$ \\
\hline Airway obstruction & $1(1.5 \%)$ \\
\hline
\end{tabular}




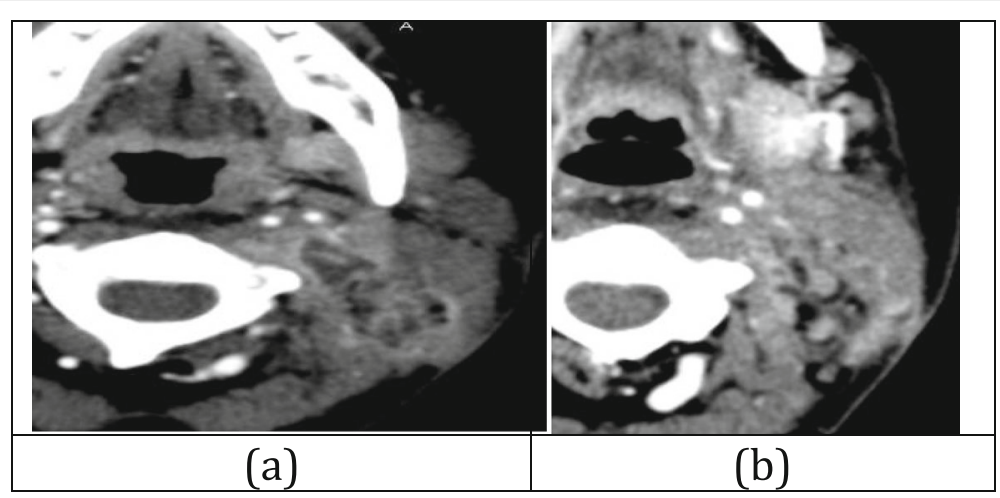

Fig. 2 A 45-year-old male with odontogenic masticator abscess. Images reveal dental and peri-dental mandibular molar disease is seen in a and left masticator abscess is seen within medial pterygoid muscle showing just fluid attenuation and ill-defined rim sign in $\mathbf{b}$. The lateral pterygoid muscle shows mild diffuse enlargement and hypo-enhancement (myositis)

The most common space involved by collections was the masticator involved in 15 cases. Out of the 15 cases of masticator space involvement, 7 had involvement of the medial pterygoid muscle, three had involvement of lateral pterygoid, while one case had masseteric muscle involvement; the remaining 4 cases had a combination of lateral and medial pterygoid involvement, thus medial pterygoid had greater involvement (Fig. 2)

The second most common space involved by collections was the SLS; out of these, six are occurring together with the involvement of the submandibular space, and four are showing horseshoe configuration abscesses crossing the midline to contralateral sublingual space. Apart from 6 cases with combined SLS-SMS involvement, two cases had involvement of SMS and masticator spaces, and one shows involvement of the visceral space in combination with SMS. The para-pharyngeal key space always showed signs of inflammation like veiling and stranding and still was not the epicenter of inflammation or showed the main burden of collection.

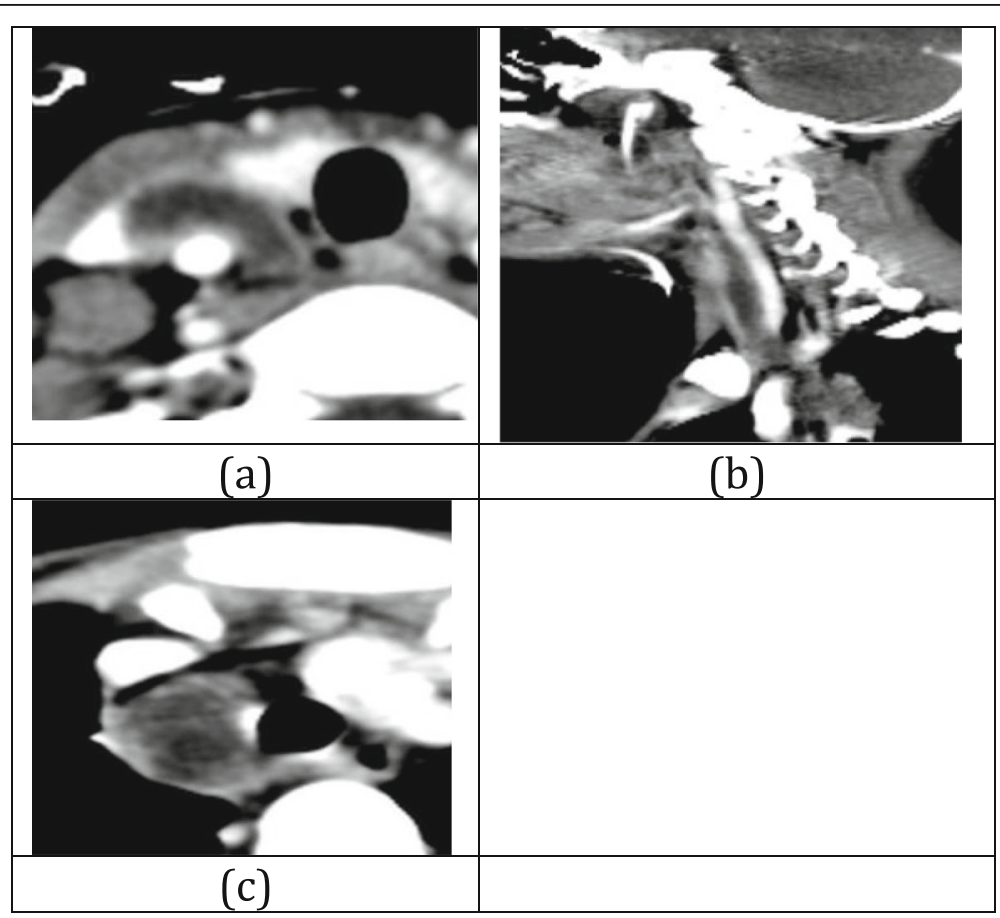

Fig. 3 A case of necrotizing fasciitis in a 55-year-old male. a-c Characteristic features of marked edema of submandibular fascial planes, both superficial and deep planes. Markedly thickened enhanced superficial layer of deep fascia is seen with areas of interrupted enhancement (necrotized fascia), with multiple fluid collections seen at anterior deep cervical space and intramuscular within strap muscle son both sides. Axial high-resolution bone window image (d) shows bilateral multifocal dental/peri-dental disease (underlying cause) 
A single case had definite radiological and clinical evidence of necrotizing fasciitis (Fig. 3). The CT revealed interrupted enhancement of thick enhancing platysma (superficial cervical fascial enhancement), suggestive of necrotized fascia, with extensive loculated submandibular and sublingual abscess, crossing the midline and dissecting down into the anterior cervical fascial space. Minimal dental disease at mandible could be the underlying disease, though very disproportionate to the burden of inflammatory exudates (Fig. 4).

Using the high-lightened imaging criteria mentioned in methodology, CT suggested a diagnosis of abscess formation in 64 patients; four out of them had signs of underlying phlegmon and proven to be non-drainable phlegmon that showed thick rim enhancement with different internal heterogeneities, sometimes engulfing cervical fat inside the peripheral granulation tissue. The fifth case (Fig. 5) was a young woman with confluent suppurative adenitis at the deep cervical nodes that had broken nodes and confluent broken-down walls and questionably internal intra-nodal abscess, shown to be non-drainable later.

The CT exam successfully excluded clinically suspect tonsillar abscess and a second case of cellulitis of buccal tissues, both responded only to medial treatment. The abscess-free tonsil revealed the striated "Tigroid- tonsil" appearance, which reflect enhancing tonsillar septa, alternating with submucosal edema. A single case of the whole 17 cases of tonsillo-pharyngitis showed small peri-tonsillar abscess easily differentiated by CT; the case deserved double catheterization (Fig. 6).

All patients with proven abscesses had peripheral "Rim" enhancement in different regularities and thicknesses; none of them failed to shows the rim sign and none showed diffuse enhancement. Agreement statistics between final surgical outcome, following drainage made by the ENT surgeon, revealed that correct diagnoses of the drainable abscess were made in 59 patients out of 64 patients with radiological diagnosis of abscess versus 5 patients falsely diagnosed to have abscesses who turned out to have nondrainable phlegmons (Table 4).

\section{Discussion}

Deep neck abscesses still impose diagnostic and treatment challenges. Although successful conservative nonsurgical treatment of small abscesses $(<3 \mathrm{~cm})$ has been reported in earlier studies, fewer than half (47.5\%) of the patients were treated with antibiotic therapy alone with complete remission in that study. Still, the mainstay of

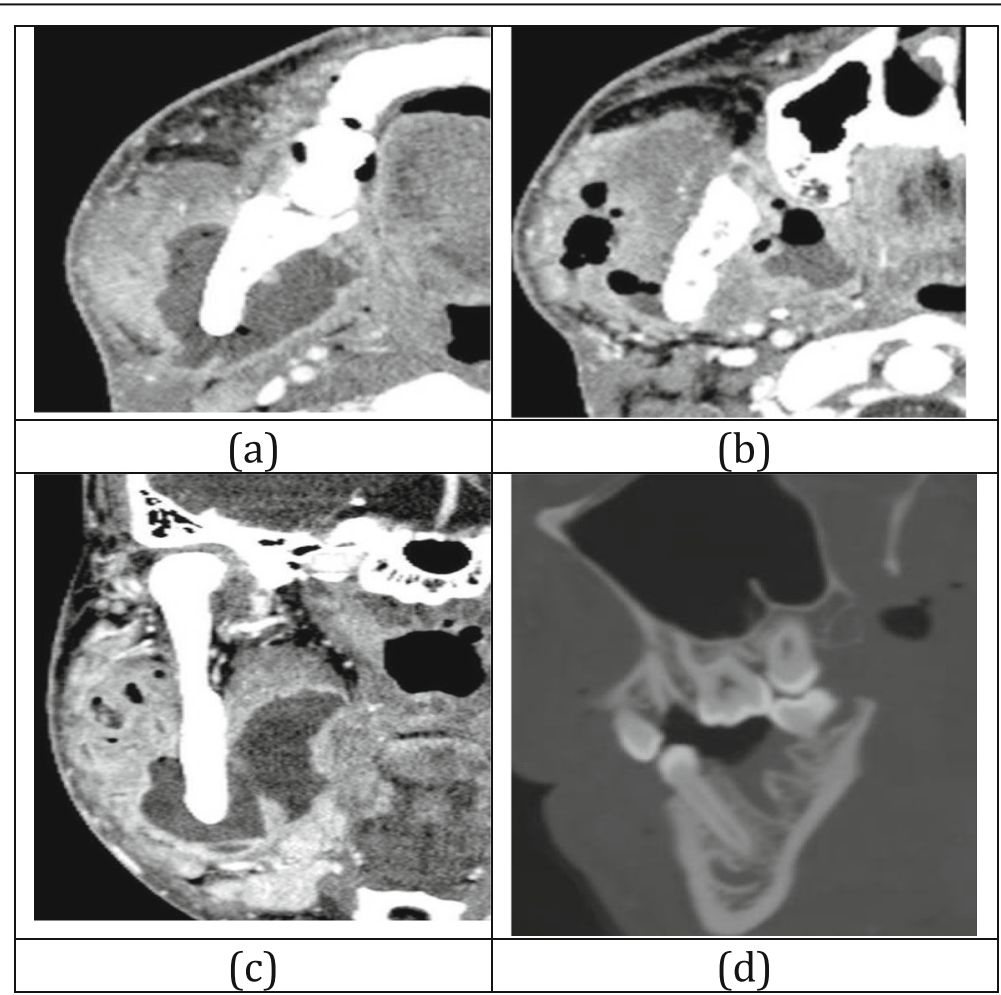

Fig. 4 A 30-year-old male with odontogenic masticator abscess. Axial images in a and $\mathbf{b}$ show well-defined rim sign provided by good biphasic technique. Also noted fluid collection (10-20 HU) and air foci within abscess collection and masseteric and pterygoid muscular compartments. Coronal image (c) shows communication below the mandible. Sagittal image (d) reveals residual peri-dental disease following extraction of unhealthy dental disease 


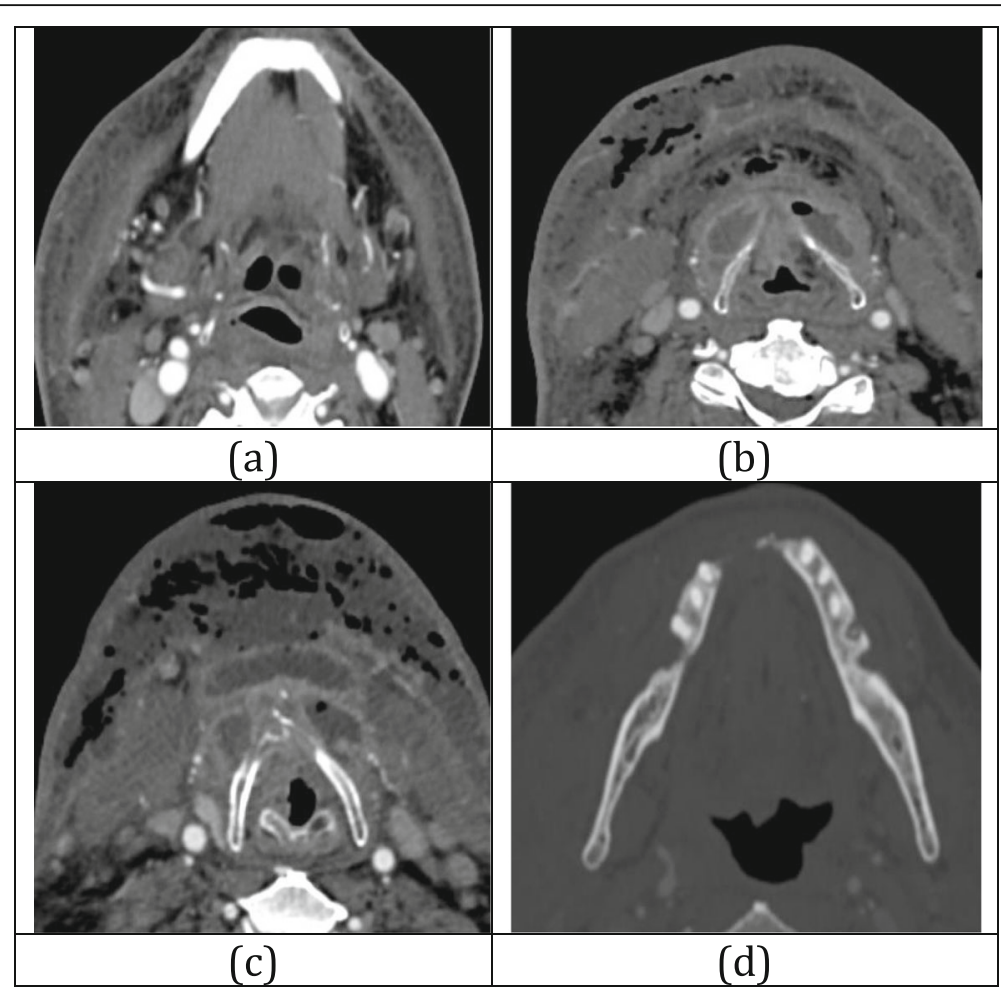

Fig. 5 A 32-year-old female with left-sided suppurative adenitis. a Intra-nodal abscess, shown as thick rim sign and complex fluid of 30-35 HU, which is slightly higher than usual fluid attenuation still considered fluid in our study. Lower axial scans in $\mathbf{b}$ show small reactive nodes

treatment for deep neck abscesses remains surgical drainage. Review of literature shows many similarities and few differences. Our series showed the DNI was twice more common in males as many authors have reported [23, 24].

Tung et al. [25] and Gerd et al. [26] have reported in their study on DNSI that the most common site of infection was the parapharyngeal space and was seen in 71 (38.4\%) and 138 (59\%) cases, respectively. In our patients, sublingual space showed the highest involvement (15 cases), followed by SLS and SMS occurring in the same proportion $(13=19.7 \%)$. On the other hand, Staflors et al. [27] in their study concurred with Tung et al.'s study reporting that the parapharyngeal space involvement was more common. Still, Kumar et al. [28] and Meher et al. [29] showed that the submandibular space was the most common site encountered. A cutoff differentiation between abscesses and cellulitis is important for an appropriate treatment plan. Contrastenhanced CT scanning has become the preferred diagnostic method. Holt et al. [30] defined and delineated the hallmarks of the diagnosis of an abscess as cystic appearance, low-density CT number, fluid or gas within the center of the abscess, and peripheral rim enhancement of the abscess wall.

However, there are still some limitations affecting the differentiation of abscesses and cellulitis or phlegmons by CT scan. The false-positive rate was found to be 30 to $40 \%$ for the prediction of abscess by $\mathrm{CT}$ scans based on imaging criteria of hypo-dense core or fluid collections. A study by Chuang et al. revealed that the PPV could reach $87.9 \%$ if rim enhancement was also included in the diagnostic criteria. They showed that the true-positive group tends to have peripheral rim enhancement or air collections [31]. However, 27.1\% of their true-positive group had no rim enhancement and $39.4 \%$ of the false-positive group presented with rim enhancement. Elden et al. [32] stated that rim enhancement was presented in both abscesses and cellulitis and, more rarely, was absent in some abscesses. However, Miller et al. [33] also reported that $9 / 20(45 \%)$ patients with a drainable collection in their study did not have rim enhancement on CT images. The presence of rim enhancement depends on the evolution of the abscess. They conclude that rim enhancement is not a good single predictor for the presence of an abscess.

Miller et al. [33] made a blinded comparison to identify the accuracy of CT. Before CECT, a surgeon recorded clinical data and predicted the extent of infection. A head and neck neuro-radiologist, blinded to the clinical evaluation, predicted the extent of infection based on CECT. The final outcome (the presence of a purulent collection) was determined at surgery or in 


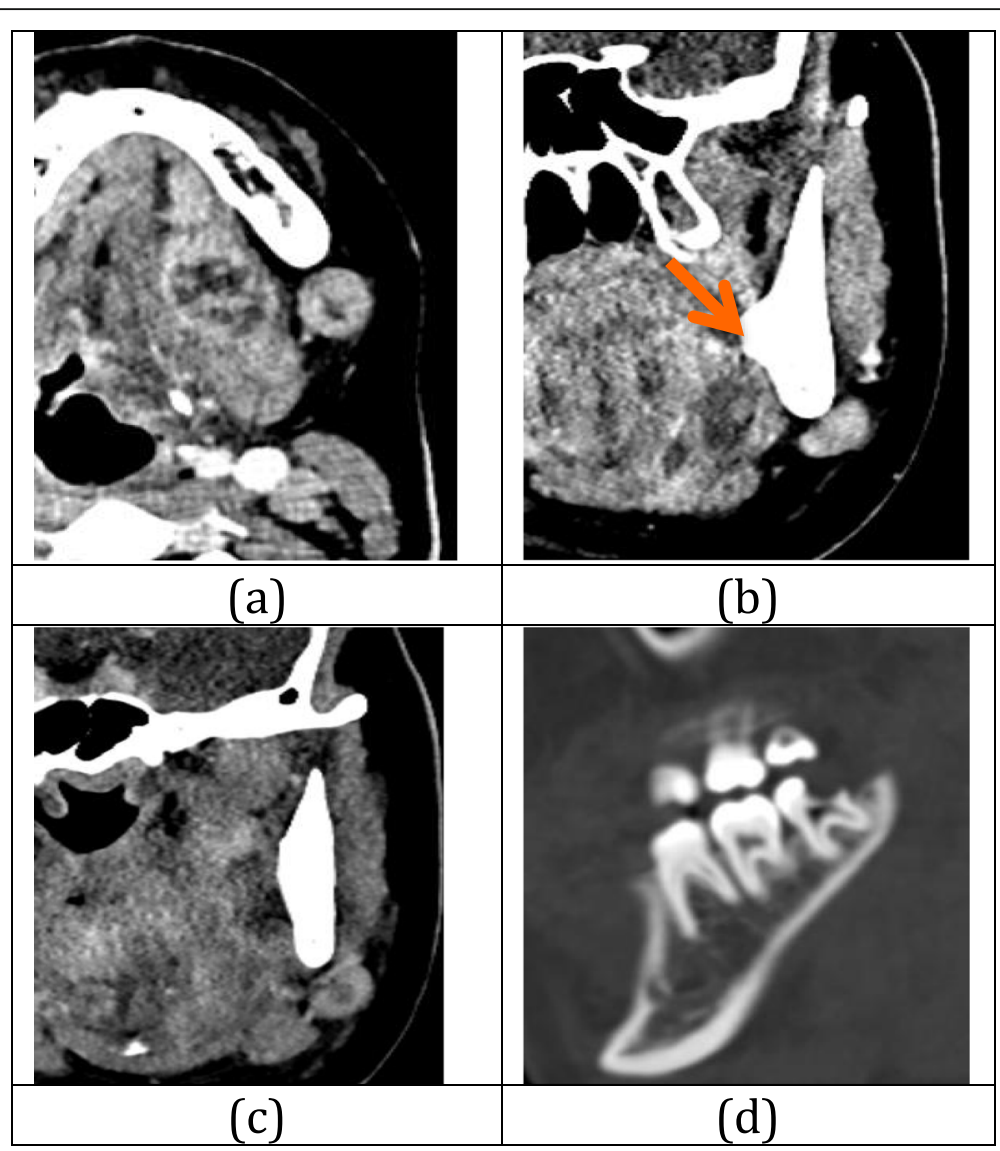

Fig. 6 Axial images of a 17-year-old male patient. Axial images at different levels (a and $\mathbf{b}$ ) reveal left-sided suppurative retropharyngeal node showing unilateral location, rounded configuration, and rim sign of intra-nodal abscess. This is easily differentiated from midline minimal retropharyngeal edema (not abscess) showing clear fluid attenuation and absence of rim sign

long-term follow-up. The clinical and CECT findings were compared with the final outcome to determine the sensitivity, specificity, and accuracy of each modality. Results: Twenty patients had purulent drainable collections. The accuracy of clinical examination alone in identifying a drainable collection was $63 \%$, the sensitivity was $55 \%$, and the specificity was $73 \%$. The accuracy of CECT alone was $77 \%$, the sensitivity was $95 \%$, and the specificity $53 \%$. When CECT and clinical examination were combined, the accuracy in identifying a drainable collection was $89 \%$, the sensitivity was $95 \%$, and the specificity $80 \%$. If fluid collections with volumes of $2 \mathrm{~mL}$ or greater on CECT were considered, the accuracy of
CECT would have been $85 \%$, the sensitivity $89 \%$, and the specificity $80 \%$ [34].

As regards the retropharyngeal collection, Hoang et al. [35] studied a four-step approach to differentiate the three entities of retropharyngeal edema, forming retropharyngeal abscess, and the third is retropharyngeal suppurative adenitis. Their four-step approach was adopted in our study. They found that four-step imaging assessment with multi-planar imaging will help to recognize key imaging findings of the three entities [36]. Also, the multiplanar and contrast-enhanced ability of CT also allowed for good assessment of mediastinal extension by another pathway along the carotid sheath which serves

Table 4 Agreement (sensitivity, specificity, and accuracy) for CT as compared to surgical diagnosis by drainage $(n=66)$

\begin{tabular}{|c|c|c|c|c|c|c|c|}
\hline & \multicolumn{2}{|c|}{ Surgical } & \multirow[t]{2}{*}{ Sensitivity } & \multirow[t]{2}{*}{ Specificity } & \multirow[t]{2}{*}{ PPV } & \multirow[t]{2}{*}{ NPV } & \multirow[t]{2}{*}{ Accuracy } \\
\hline & Not & Abscess & & & & & \\
\hline \multicolumn{8}{|l|}{$\mathrm{CT}$} \\
\hline Not abscess & 2 & 0 & 100.0 & 28.57 & 92.19 & 100.0 & 92.42 \\
\hline Abscess & 5 & 59 & & & & & \\
\hline
\end{tabular}

$P P V$ positive predictive value, $N P V$ negative predictive value 
as a direct pathway of spread, called Lincoln's highway. This is different from the intravascular spread through IJV thrombo-phlebitis \pm Lemierre syndrome $[37,38]$.

In our study, all patients with final radiological and surgical diagnoses of abscesses had peripheral rim enhancement of variable thickness. Owing to the high dose of injected contrast and double technique of rapid and slow impregnation methods of injections, the wall of the abscess should enhance regardless to the degree of evolution or maturation. An abscess with non-enhancing rim is remotely possible with the use of such biphasic CT technique. The phlegmons on the other hand had a variable enhancement pattern. The peripheral rim pattern was thicker than that for abscesses and less defined as well as less degree of enhancement. Others showed diffuse hypo- or slight hyper-enhancement in abscess of definite hypo-dense cores. Owing to the impregnation technique, the center of the phlegmon was given time to enhance slowly respective to the hypo-vascular density of its core, as compared to liquefied necrotic of the abscess which should not enhance at all and would give near fluid attenuation. The biphasic injection method is a very good technique to enhance tissue and vessel attenuation and is recommended to be included in routine imaging of the neck [39-45].

\section{Conclusion}

The use of biphasic CT (biphasic implies two phases and single scanning phase) allowed more accurate discrimination of abscess from the phlegmon by using certain imaging criteria. This is attributable to the impregnation technique (slower first phase) allowing enhancement of the hypo-dense center of phlegmon and appearing differently from an abscess. While dual injection allowed the enhancement of "Rim-enhancing pattern" in abscesses with immature walls, all abscess expressed "rim sign."

\section{Abbreviations \\ DNI: Deep neck infections; CT: Computed tomography; SMS: Submandibular space; SLS: Sublingual abscess; PPS: Parapharyngeal space; \\ RPS: Retropharyngeal space; MS: Masticator space; CS: Carotid space; ACS: Anterior cervical space; VS: Visceral space; IJV: Internal jugular vein; TGC: Thyro-glossal cyst; MRI: Magnetic resonance imaging; PPV: Positive predictive value; NPV: Negative predictive value}

\section{Acknowledgements}

Not applicable

\section{Authors' contributions}

This study was established by two authors. Both authors, "LE" and "AM," have read and approved the manuscript and ensured that this is the exact study.

\section{Funding}

No funding was received for establishing this study from any institutional or private premise

\section{Availability of data and materials}

Data sharing is not applicable to this article as no datasets were generated or analyzed during the current study.

\section{Ethics approval and consent to participate}

The Ethical committee at Alexandria University approved our research. A written Consent to Participate' in this study was obtained from all cases included in this study, or their parent or legal guardian in the case of children under 16

\section{Consent for publication}

It was included in the written consent to participate in the study by the cases or the care providers for cases below 16 years.

\section{Competing interests}

We declare no conflict of interest.

\section{Author details}

${ }^{1}$ Radiology Department, Alexandria Faculty of Medicine, Alexandria, Egypt. ${ }^{2}$ Otolaryngology Department, Alexandria Faculty of Medicine, Alexandria, Egypt.

Received: 3 April 2020 Accepted: 29 September 2020

Published online: 21 October 2020

\section{References}

1. Wang LF, Kuo WR, Tsai SM, Huang KJ (2003) Characterizations of lifethreatening deep cervical space infections: a review of one hundred ninetysix cases. Am J Otolaryngol 24:111-117

2. Parhiscar A, Har-El G (2001) Deep necks abscess: a retrospective review of 210 cases. Ann Otol Rhinol Laryngol 110:1051-1054

3. Wang LF, Kuo WR, Tsai SM, et al. Characterizations of life-threatening deep cervical space infections: a review of one hundred ninety-six cases. Am J Otolaryngol. 2003;24:111-7.

4. Nasir SB, Shuaibu IY, Labaran SA, Inusa AA (2019) Management of deep neck space infections in a tertiary center in North West Nigeria. Niger J Surg 25(2):183-187

5. Kumar NJ, Rayanan SG, Greeshma G (2017) A study on deep neck space infections. Otolaryngol Online J 7(4):1-6

6. Wong TY (1999) A nationwide survey of deaths from oral and maxillofacial infections: the Taiwanese experience. J Oral Maxillofac Surg 57:1297-1299

7. Huang TT, Liu TC, Chen PR, Tseng FY, Yeh TH, Chen YS (2004) Deep neck infection: analysis of 185 cases. Head Neck 26:854-860

8. Bottin R, Marioni G, Rinaldi R, Boninsegna M, Salvadori L, Staffieri A (2003) Deep neck infection: a present- day complication. A retrospective review of 83 cases (1998-2001). Eur Arch Otorhinolaryngol 260:576-579

9. Eftekharian A, Roozbahany NA, Vaezeafshar R (2009) Deep neck infections: a retrospective review of 112 cases. Eur Arch Otorhinolaryngol 266:273-277

10. Yonetsu K, Izumi M, Nakamura T (1998) Deep facial infections of odontogenic origin: CT assessment of pathways of space involvement. AJNR Am J Neuroradiol 19:123-128

11. Capps RF, Kinsella JJ, Gupta M, Bhatki AM, Opatowsky MJ (2010) Emergency imaging assessment of acute, non- traumatic conditions of the head and neck. RadioGraphics 30:1335-1352

12. Kubal WS (2015) Face and neck infections. Radiologic Clinics of North America 53(4):827-846

13. Wang B, Gao BL, Xu GP, Xiang C (2014) Images of deep neck space infection and the clinical significance. Acta Radiol 55:945-951

14. Crespo AN, Chone CT, Fonseca AS (2004) Clinical versus computed tomography evaluation in the diagnosis and management of deep neck infection. Sao Paulo Med J 122:259-263

15. Smith JL 2nd, Hsu JM, Chang J: Predicting deep neck space abscess using computed tomography. Am J Otolaryngol 2006; 27:244-247.

16. Freling N, Roele E, Schaefer-Prokop C (2009) Ockens. Prediction of deep neck abscesses by contrast-enhanced computerized tomography in 76 clinically suspect consecutive patients. Laryngoscope 119:1745-1752

17. Maroldi R, Farina D, Ravanelli M, Lombardi D, Nicolai P. Emergency imaging assessment of deep neck space infections. Seminars in US, CT and MRI 2010; 423- 42

18. Vural C, Gungor A, Comerci S (2003) Accuracy of computerized tomography in deep neck infections in the pediatric population. Am J Otolaryngol 24(3): 143-148

19. Carbone PN, Capra GG, Brigger MT. Antibiotic therapy for pediatric deep neck abscesses: a systematic review. Int J Pediatr Otorhinolaryngol. 2012;76: 1647-53. 
20. Kirse DJ, Roberson DW (2001) Surgical management of retropharyngeal space infections in children. Laryngoscope 111(8):1413-1422

21. Vieira F, M.Allen SH, S.Stocks, RM, W.Thompson J. Otolaryngologic Clinics of North America 2008; 41 (30): 459-83.

22. Lee J, Kim H, Lim S (2007) Predisposing factors of complicated deep neck infection: an analysis of 158 cases. Yonsei Med J 48(1):55-62

23. Babu VR, Ikkurthi S, Perisetty DK, Saran Babu KA, Rasool M, Shaik SK (2018) A prospective comparison of computed tomography and magnetic resonance imaging as a diagnostic tool for maxillofacial space infections. J Int Soc Prev Community Dent 8(4):343-348

24. Sethi DS, Stanley RE (1994) Deep neck abscesses: changing trends. J Laryngol Otol 108:138-143

25. Huang TT, Liu TC, Chen PR, Tseng FY, Yeh TH (2004) Deep neck infection: analysis of 185 cases. J Otolaryngol Head Neck Surg 26:854-860

26. Ridder GJ, Technau-Ihling K, Sander A, Boedeker CC (2005) Spectrum and management of deep neck space infections: an 8-year experience of 234 cases. Otolaryngol Head Neck Surg 133:709-714

27. Kauffmann PH, Cordesmeyer R, Tröltzsch M, Sömmer C, Laskawi R (2017) Deep neck infections: a single-center analysis of 63 cases. Med Oral Patol Oral Cir Bucal 22(5):536-541

28. Kumar NJ, Sankaranaarayanan G, Greeshma G. A study on deep neck space infections. Otolaryngol Online J 2017; 7 (3): 159 :1-4.

29. Stalfors J, Adielsson A, Ebenfelt A, Nethander G, Westin T (2004) Deep neck space infections remain a surgical challenge. A study of 72 patients. Acta Oto Laryngol 124:1191-1196

30. Meher R, Jain A, Sabharwal A, Gupta B, Singh I (2005) Deep neck abscess: a prospective study of 54 cases. J Laryngol and Otology 119:299-302

31. Holt GR, McManus K, Newman RK, Potter JL, Tinsley PP (1982) Computed tomography in the diagnosis of deep-neck infections. Arch Otolaryngol 108(11):693-696

32. Chuang SY, Lin HT, Wen YS, Hsu FJ (2013) Pitfalls of CT for deep neck abscess imaging assessment: a retrospective review of 162 cases. B-ENT 9 : 45-52

33. Elden LM, Grundfast KM, Vezina G (2001) Accuracy and useful- ness of radiographic assessment of cervical neck infections in children. J Otolaryngol. 30(2):82-89

34. Miller WD, Furst IM, Sa` n GK (1999) A prospective, blinded comparison of clinical examination and computed tomography in deep neck infections. Laryngoscope 109:1873-1879

35. Hoang JK, Branstetter BF, Eastwood JD, Glastonbury CM (2011) Multiplanar CT and MRI of collections in the retropharyngeal space: is it an abscess? AJR 196:426-432

36. Bidkar V, Naik A, Shanbag R, Jalisattigi R, Rashmi S (2013) An unusual infection of visceral compartment of the neck following retropharyngeal space infection. J Dent Med Sci 5(6):9-13

37. Patigaroo SA, Lone ZA, Batool QA, Qazi SM (2017) Lincoln 'S highway - a forgotten abscess. Heighpubs Otolaryngol Rhinol 1:011-015

38. Alves S, Stella L, Carvalho I, Moreira D (2019) Lemierre's syndrome: a disguised threat. BMJ Case Rep 12(4):1-3

39. Groell R, Doer er O, Schaf er GJ, Habermann W (2001) Contrast- enhanced helical CT of the head and neck: improved con- spicuity of squamous cell carcinoma on delayed scans. AJR Am J Roentgenol 176:1571-1575

40. Bartz BH, Case IC, Srinivasan A, Mukherji SK (2006) Delayed MDCT imaging results in increased enhancement in patients with head and neck neoplasms. J Comput Assist To- mogr 30:972-974

41. Priyamvada S, Motwani G (2019) A study on deep neck space infections. Indian J Otolaryngol Head Neck Surg 71(2):1-5

42. Lee JH, Ryu CW, Kim SM, Kim EJ, Choi WS (2012) Usefulness of biphasic contrast injection in multi-detector $\mathrm{CT}$ of the head and neck: a comparison with monophasic contrast injection. J Korean Soc Radiol 67(2):85-92

43. Harris EW, LaMarca AJ, Kondroski EM, Murtagh FR, Clark RA (1996) Enhanced $\mathrm{CT}$ of the neck: improved visualization of lesions with delayed imaging. Am J Roentgenol 167:1057-1058

44. Wang B, Gao BL, Xu GP, Xiang C (2014) Images of deep neck space infection and the clinical significance. Acta Radiol 55(8):945-951

45. Coelho M, Ramos G, Prestes LC, Soccol AB, de Oliveira MC, Lobo P (2009) Deep neck infections - classification in levels of severity. Intl Arch Otorhinolaryngol 13(2)):184-188

\section{Publisher's Note}

Springer Nature remains neutral with regard to jurisdictional claims in published maps and institutional affiliations.

\section{Submit your manuscript to a SpringerOpen ${ }^{\circ}$ journal and benefit from:}

- Convenient online submission

- Rigorous peer review

- Open access: articles freely available online

- High visibility within the field

- Retaining the copyright to your article

Submit your next manuscript at $\boldsymbol{\nabla}$ springeropen.com 